\title{
Coronary and peripheral vascular occlusion due to rheumatoid arteritis
}

\author{
*S. R. RUDGE \\ M.B., M.R.C.P.
}

\author{
J. K. LLOYD JONES \\ M.A., F.R.C.P.
}

\author{
A. Macfarlane \\ F.R.C.P., F.R.C.Path.
}

Harlow Wood Orthopaedic Hospital, Mansfield, Notts

\begin{abstract}
Summary
A case of severe progressive rheumatoid arteritis leading to bilateral lower limb amputation and death from myocardial infarction is described.
\end{abstract}

\section{Introduction}

Vasculitis is a well recognized complication of rheumatoid arthritis tending to occur in individuals with severe seropositive nodular disease. It commonly affects small vessels, particularly the digital arteries where the lesion is usually intimal proliferation without significant arterial wall necrosis. Focal ischaemic micro-infarction often occurs, occasionally leading to localized gangrene. Involvement of major vessels is less well recognized although abdominal apoplexy (Webb and Payne, 1970), cerebral vasculitis (Ramos and Mandybur, 1975) and coronary arteritis (Baggenstoss and Rosenberg, 1941) have been described. No reports, it seems, exist of iliac artery occlusion.

\section{Case report}

The patient was a 53-year-old white male who originally worked as a fitter with an engineering company and later as the licensee of an off-licence. He had smoked 30 cigarettes/day throughout his life, rarely drank alcohol and was well before developing rheumatoid disease at the age of 43 . He had no previous history of chest pain, peripheral ischaemic or other circulatory symptoms. There was no family history of coronary artery disease, hypertension or diabetes. In April 1969 he developed pain and stiffness in both knees and ankles. On examination he was found to have active synovitis in both wrists, both ankles and both knees with bilateral knee effusions. There were no rheumatoid nodules or vasculitis. Blood pressure was $130 / 80 \mathrm{mmHg}$. Examination of the cardio-vascular system and chest was normal and all peripheral pulses were palpable. There was no peripheral neuropathy.
Hb was $10 \cdot 4 \mathrm{~g} / \mathrm{dl}$. ESR $65 \mathrm{~mm} / \mathrm{hr}$ (Westergren). Slide latex test positive. Rose Waaler test positive $1 / 640$. Urea $3 \cdot 1 \mathrm{mmol} / \mathrm{l}$. Sodium $136 \mathrm{mmol} / \mathrm{l}$. Potassium $4.1 \mathrm{mmol} / 1$. Blood sugar $4.9 \mathrm{mmol} / \mathrm{l}$. MSU showed no protein or cells. ECG was normal. X-rays of chest, hands and wrists were normal. X-ray of $\bar{z}$ knees showed large osteophytes in the right medial compartment. X-ray of the feet showed a possible erosion in the right middle metatarsal head. $\overrightarrow{0}$ diagnosis of seropositive rheumatoid arthritis wa্ made and treatment was started with soluble aspirin and ibuprofen with marked symptomate relief.

In 1973 his right knee became infected with a Lancefield Group G $\beta$-haemolytic Streptococcus and in early 1974 a Staphylococcus pyogenes infection developed in the interphalangeal joint of the left big toe. Both infections required surgical drainage and i.v. antibiotics. On each occasion he made a good recovery.

In October 1975 he developed multiple periungual infarcts and several subcutaneous nodules with overlying vasculitic lesions. Investigations at this time showed a $\mathrm{Hb}$ of $12.9 \mathrm{~g} / \mathrm{dl}$, an ESR $56 \mathrm{~mm} / \mathrm{hr}$ and a Rose Waaler test positive 1/128. D-Penicillamine was started and increased gradually to a dose of one g/day. However, vasculitic lesions continued to appear and penicillamine was judged ineffective in January 1977 and stopped. Azathioprine $50 \mathrm{mg}$ twice daily was introduced early in 1978 with initial o good effect. This was short-lived and despite its $N$ continuation throughout most of the rest of his $\mathrm{N}$ illness crops of vasculitic lesions continued to $\omega$ appear. At no time did he receive corticosteroids.

In March 1978 he developed severe pain in his

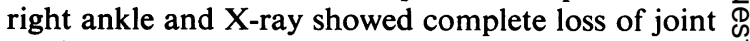
cartilage, and underlying bony erosions. A silastic interposition arthroplasty was performed. Wound closure was delayed and, despite a skin graft later that year, healing failed to occur. In December 1978 
deep ulcers appeared in the left ankle and thereafter became infected. By June 1979 he was experiencing severe rest pain from the left foot. Examination revealed absent foot pulses on both sides, an absent left femoral pulse and a right femoral bruit. There was no peripheral neuropathy. Reconstructive surgery and arteriography were felt to be contra-indicated and he underwent left below-knee amputation with immediate pain relief. However, by August he had developed severe rest pain at the site of the right inter-position arthroplasty which had remained unhealed. Right below-knee amputation was performed in September but within one month he was experiencing severe rest pain from both amputation stumps, neither of which showed any evidence of healing. Azathioprine was discontinued. The right femoral pulse was now absent. BP, ECG, estimations of urea and electrolytes and urinalysis were all normal. Plans for bilateral above-knee amputation were under discussion when, without warning, he had a sudden cardiac arrest and died. At no time had he complained of chest pain.

At post-mortem the heart showed an organizing infarct $4 \mathrm{~cm}$ across in the upper part of the posterior wall of the left ventricle. There was complete occlusion of the right coronary artery $1 \mathrm{~cm}$ from its origin by atheroma and organizing thrombus. Mild atheroma was present in the anterior and circumflex branches and moderate atheroma in the lower abdominal aorta with overlying thrombus. Both common iliac arteries were occluded at their midpoints by apparent atheroma and organizing thrombus, while the external iliacs and femoral arteries were healthy. The pelvic and leg veins were not involved. The kidneys and lungs were macroscopically normal.

Microscopically the common iliac and right coronary arteries showed intense infiltration of all coats by lymphocytes and plasma cells (Figs 1 and 2). There was fibrous thickening in the intima of each artery which merged with organizing thrombus occluding the lumen. Giant cells and fibrinoid necrosis were not seen. No evidence of small artery involvement was found in the myocardium. In the skin adjacent to the peri-ungual ulcers there was an occlusive vasculitis involving small vessels.

\section{Discussion}

Although coronary artery involvement in rheumatoid arthritis is well recognized, its role in the aetiology of myocardial infarction is more controversial. Cruikshank (1954) found a subacute arteritis

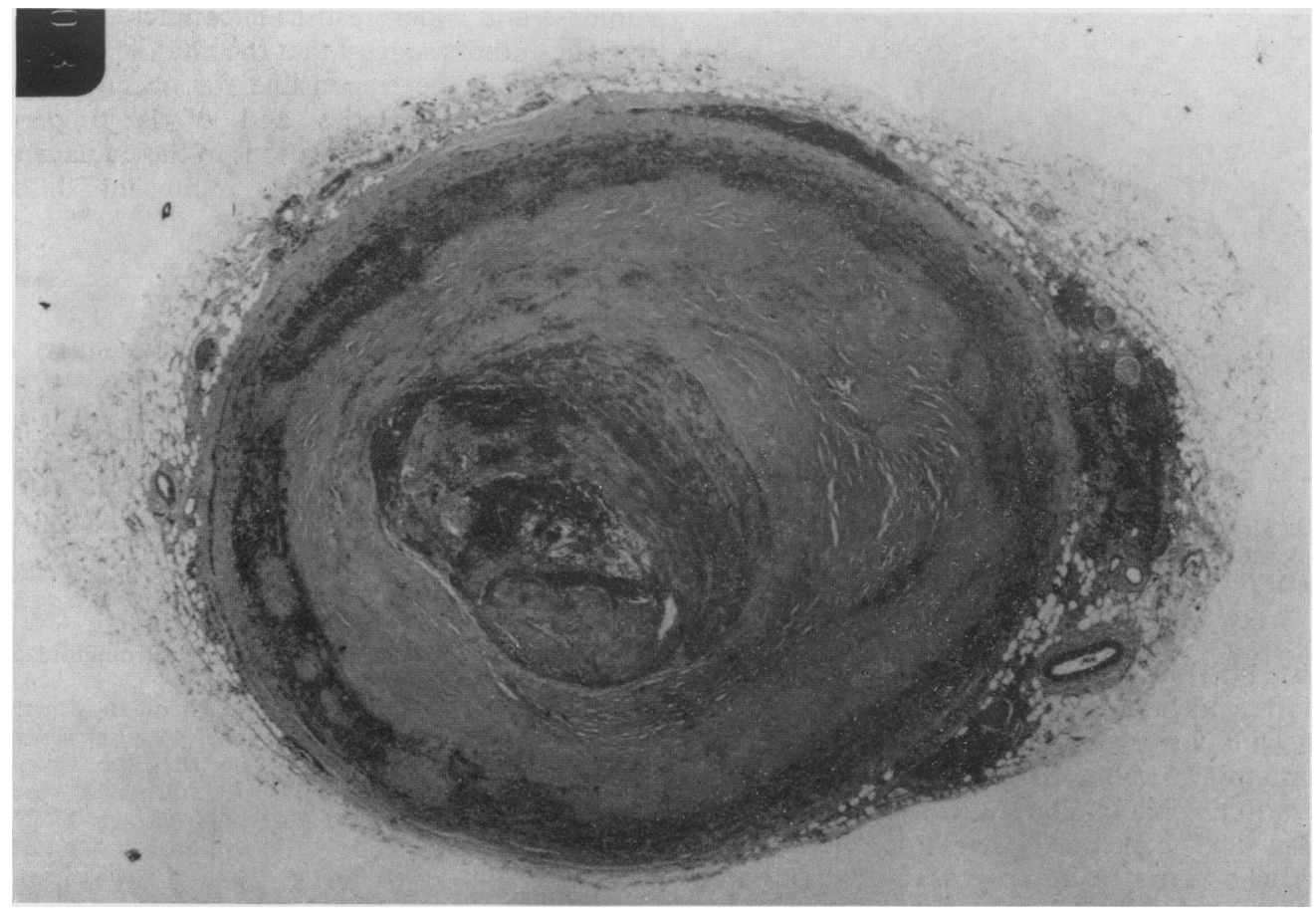

FIG. 1. Right coronary artery showing intense infiltration of all coats by inflammatory cells, atheromatous thickening of the intima and organizing thrombus occluding the lumen (HE, $\times 3.5$ ), 
affecting the small coronary vessels in $20 \%$ of postmortems on rheumatoid patients. Similar figures were obtained by Lebowitz (1963). Most of the lesions described appear relatively benign although Lebowitz reported 2 patients in whom arteritis in its more florid form masqueraded clinically as atherosclerotic heart disease. Both died from cardiac arrhythmias and at post-mortem the myocardium in one revealed a diffuse healing arteritis. However, in neither case was there evidence of main coronary artery occlusion leading to myocardial infarction.

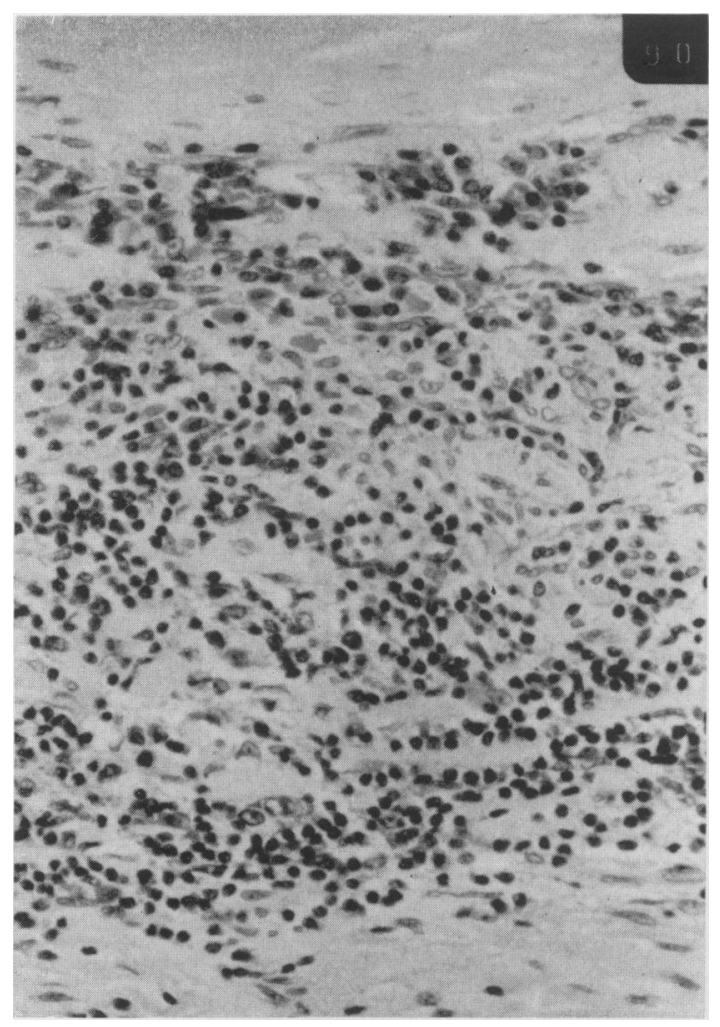

FIG. 2. High power view showing infiltration of the arterial wall by lymphocytes, plasma cells and histiocytes $(\mathrm{HE}, \times 300)$.

Levin (1955) reported that 5 of 7 myocardial infarctions which occurred in 43 post-mortems of patients with rheumatoid arthritis were attributable to rheumatoid arteritis. Swezey (1967) described a patient with angina who later died from myocardial infarction and concluded that 'the majority of patients who came to autopsy with an associated myocardial infarction and rheumatoid arthritis have had coronary arteritis as the underlying cause of the infarction'. However, a large series carried out by
Karten (1969) would suggest that this is not so. $\frac{\mathbb{1}}{\mathrm{D}}$ From 197 post-mortems examined, evidence of

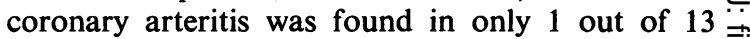
patients with rheumatoid arthritis dying from myo- $\stackrel{\vec{S}}{+}$ cardial infarction. So, although subacute arteritis is $\overline{0}$ commonly present in rheumatoid patients, there is $\bar{\sigma}$ no clear evidence that arterial occlusion caused by $\frac{\bar{m}}{7}$ the vasculitis is a common cause of infarction.

So far as the authors are aware there are no reports of rheumatoid arteritis causing large peripheral s artery occlusion. Although macroscopically the $\odot$ lesions in the common iliac artery and in the right $\overrightarrow{\vec{\omega}}$ coronary artery appeared to be the result of throm- $\sigma$ bosis on top of atheroma, the unusual symmetrical 8 siting of these changes in the common iliac arteries 3 . with healthy arteries beyond prompted histological if examination of all 3 arteries. This clearly demonstrated that the primary event was inflammatory of rather than atherosclerotic. Since the patient was a $\vec{\bullet}$ heavy cigarette smoker, an alternative diagnosis of $\mathscr{C}$ thrombo-angeitis obliterans (Buerger's disease) was considered. However, the lack of venous involve- ment, the absence of giant cells and the concurrent $z$ involvement of the coronary arteries make this diagnosis unlikely. The absence of fibrinoid necrosis $\supset$ excludes polyarteritis nodosa. Although inflamm $\vec{B} \overrightarrow{0}$ tory cell infiltration of the adventitia is often seen relation to atheromatous plaques it is never intense and widespread as encountered here.

The authors suggest that rheumatoid arteritis may, on occasion, be responsible for occlusion both of the coronary arteries and of large peripheral $\stackrel{\circ}{\perp}$ arteries. This has implications in the management of such patients and is an important differential 0 diagnosis to bear in mind.

\section{References}

Baggenstoss, A.H. \& Rosenberg, E.R. (1941) Cardiac lesions associated with chronic infectious arthritis. $\bar{\sigma}$ Archives of Internal Medicine, 67, 241.

Bywaters, E.C.L. (1957) Peripheral vascular obstruction in rheumatoid arthritis and its relationship to other vascular lesions. Annals of the Rheumatic Diseases, 16, 84.

Cruikshank, B. (1954) The arteritis of rheumatoid arthritis. 윽 Annals of the Rheumatic Diseases, 13, 136.

KARTEN, I. (1969) Arteritis, myocardial infarction and $\frac{D}{O}$ rheumatoid arthritis. Journal of the American Medical Association, 210, 1717.

LEBowitz, W.B. (1963) The heart in rheumatoid arthritis. of Annals of Internal Medicine, 58, 102.

LEVIN, M.H. (1955) The heart in rheumatoid arthritis: a NN clinical-pathological correlation of 43 autopsied patients. $\omega$ Annals of the Rheumatic Diseases, 14, 430.

Ramos, M. \& MANDYBUR, T.I. (1975) Cerebral vasculitis inco rheumatoid arthritis. Archives of Neurology, 32, 271.

SwEZEY, R.L. (1967) Myocardial infarction due to rheuma- $\mathbb{D}$ toid arteritis. Journal of the American Medical Association 199, 855.

WebB, J. \& PAYNe, W.H. (1970) Abdominal apoplexy in $\bar{D}$ rheumatoid arthritis. Australasian Annals of Medicine, 19, $\stackrel{\mathbb{Q}}{\mathbb{Q}}$ 168. 